\title{
OS USUÁRIOS DE PRODUTOS PARAESCOLARES: PAIS OU FILHOS?
}

\author{
Charles Corid IAN ${ }^{* *}$
}

\begin{abstract}
RE SU M 0 : Este artigo aborda a distinção entre usuários diretos e indiretos dos produtos educativos, no campo da formação inicial, na França. $\mathrm{O}$ autor apóia-se mais particularmente numa pesquisa realizada sobre produtos paraescolares, isto é, destinados a ajudar os alunos em seu estudo pessoal em casa. Esses produtos são tradicionalmente comprados pelos pais, que pedem que seus filhos os usam, e, já há alguns anos, eles são destinados diretamente aos pais. Os editores se dirigem a eles como se fossem verdadeiros auxiliares dos docentes. A análise percorre essa recente evolução do mercado e indaga-se sobre as conclusões que se pode tirar desse modo de envolver a responsabilidade dos pais no sucesso escolar de seus filhos.

Palavras-chaves: Produtos educacionais. Relações família-escola. Estudo de casa.
\end{abstract}

\section{THE EXTRACURRICULAR PRODUCT USERS: PARENTS OR CHILDREN?}

A BSTRA CT : This paper stresses differences between direct and indirect users of educational products in French schooling context. The author relies particularly on a survey which was focused on products intended to help pupils in their home work. If that kind of products is traditionaly bought by parents who ask their children to use them, some of these educational products are now directly devoted to parents themselves. In fact publishers address to the parents as if they were assistants for teachers. The analysis examines this recent evolution and the consequences in the manner to consider parents' responsibility in success at school.

Key words: Educational products. Family-school relationship. Home work.

\footnotetext{
* Tradução de Alain François.

* Institut National de Recherche Pédagogique, Paris. E -mail: coridian@ noos.fr
} 

escolarização, os sociólogos da educação ainda hesitam muito em recorrer à noção de usuário. Quando se empreende uma reflexão em torno do lugar dos usuários no sistema escolar, é espantoso constatar que se levam em conta apenas os pais de alunos. ${ }^{1}$ Estes, entretanto, ao contrário dos alunos que utilizam diretamente os serviços fornecidos pelo sistema escolar, não passam de usuários indiretos. Em contrapartida, no campo escolar, é preciso não superestimar a importância da noção vizinha de consumidor. Se, hoje em dia, fala-se com certa facilidade em consumismo escolar, o mercado, sem o qual não existem consumidores, continua sendo uma referência de ondem metafórica. De fato, os pais de alunos podem escolher entre o público e 0 privado e, quando têm os recursos suficientes, fazer o necessário para conseguir matricular seus filhos nos estabelecimentos que encabeçam as classificações publicadas regularmente na imprensa. Contudo, não seria exagero evocar o surgimento de uma lógica de mercado porque parte dos pais obteve uma maior liberdade de escolha dos estabelecimentos?

Em compensação, se considerarmos o que ocorre à margem da escola, é muito mais fácil encontrar verdadeiros consumidores-usuários de bens educativos. Pode-se até falar em clientes dispostos a comprar produtos ou serviços destinados a satisfazer necessidades induzidas pela escolaridade. Basta pensar, por exemplo, nos cursos particulares, mercado em relativa expansão, cuja oferta se adapta a uma demanda que evolui (Glasman et al., 1994). Enfocando um desses mercados à margem da escolaridade, vamos propor alguns elementos relativos à problemática da relação usuários indiretos/ usuários diretos no campo da educação escolar.

O mercado da edição paraescolar, que vem nos interessando (Colin \& Coridian, 1996) apresenta algumas características específicas. Assim como os cursos particulares, os produtos paraescolares são bens educativos cujos preconizadores e compradores não costumam ser usuários diretos. Os pais são quem paga cursos particulares ou livros paraescolares que seus filhos devem utilizar ou "consumir". Na realidade, a demanda para esses bens educativos não emana dos alunos do ensino fundamental. ${ }^{2}$

\section{Uns bens educativos à margem da escolaridade}

Esses elementos de reflexão sobre a noção de usuário no âmbito da formação inicial se apóiam numa pesquisa que se inscreve no campo das 
análises consagradas à evolução das formas de mobilização das famílias em torno da escolaridade de seus filhos. Mobilização essa que parece tornar-se cada vez mais necessária, uma vez que, hoje em dia, a provação da certificação escolar impõe-se a todos, e que, ao mesmo tempo, a compe tição escolar intensificou-se muito, em todos os níveis. De fato, independentemente do meio social, os pais atuais envolvem-se muito mais no monitoramento e acompanhamento da escolaridade de seus filhos. Assim, a maioria das entrevistadas revela que praticamente dois em cada três pais de alunos do segundo ciclo do ensino fundamental controlam e ajudam seus filhos em seus estudos escolares. Embora sua amplidão e suas modalidades variem segundo o meio sociocultural e a dinâmica do funcionamento familiar, em termos comportamentais, o monitoramento do estudo escolar dos filhos tende a tornar-se uma norma implícita para os pais de alunos. É nesse contexto de uma participação crescente dos pais no monitoramento e acompanhamento da escolaridade de seus filhos que a edição paraescolar se expandiu, sendo que, em contrapartida, o acompanhamento escolar dos filhos de meios desfavorecidos também cresceu muito (Glasman, 2001).

Na França, o termo 'paraescolar' designa todo um conjunto de produtos concebidos para ajudar os alunos em suas aprendizagens escolares, fora da escola. Os livros, sottwares ou sites web paraescolares, portanto, são produtos destinados a apoiar, reforçar, complementar ou aprofundar o estudo pessoal exigido dos alunos. Em meados dos anos de 1970, foi essencialmente para encontrar novas saídas nas famílias que os editores escolares tradicionais começaram a lançar no mercado novos tipos de livros de revisão, de exercícios ou de apoio. Também nessa época, voltaram a lançar a fórmula dos "cadernos de férias", ${ }^{3}$ que atravessara um período de obsolescência. Em seguida, a expansão do uso da microinformática e da Internet favoreceu o êxito de produtos multimídia e de recursos em linha, também destinados ao acompanhamento dos filhos em seus estudos. ${ }^{4}$ Por sinal, a maioria dos sites dos editores presentes no nicho escolar comprova que acabaram diversificando seus suportes e combinando a produção de livros, CD-ROMS e recursos on-line.

\section{Pais compradores, filhos usuários}

0 encontro entre a oferta de novos produtos, lançados no mercado pelas editoras, e uma demanda potencial das famílias deu-se sem maiores problemas. De fato, o aumento do desemprego e as dificuldades crescentes dos jovens para se inserirem na vida ativa contribuíram para 
fazer do êxito escolar dos filhos o cerne das preocupações dos pais. Neste sentido, tudo o que parecia suscetível de maximizar as chances de os filhos obterem melhores resultados na escola não podia senão reter a atenção dos pais. Isso provocou um forte crescimento do mercado de edição paraescolar.

Portanto, parte dos pais de alunos compra produtos paraescolares - cadernos ou livros de exercícios, de apoio, de aprofundamento, softwares etc. - para seus filhos, porque desejam ajudá-los a estudar em casa ou para lhes fornecer instrumentos de estudo que, supostamente, vão facilitar sua tarefa ou, melhor ainda, motivá-los a envidar os esforços necessários a uma boa escolaridade. Obviamente, com alunos do ensino fundamental, são os pais que compram os produtos paraescolares. Por sinal, o discurso promocional dos editores dirige-se quase exclusivamente aos pais, pois são eles que é preciso convencer do interesse de comprar cadernos de exercícios ou livros de revisão para estudar em casa. 0 que não significa que os editores não recorram a procedimentos destinados a reter a atenção dos alunos. Mais particularmente no caso de vendas em supermercados, eles buscam instigar o que os especialistas em marketing chamam de "compra impulsiva" por meio, por exemplo, da escolha judiciosa das cores de capas e dos temas dos livros ou ainda da referência a personagens de filmes etc. Globalmente, no caso do material paraescolar destinado aos alunos do ensino fundamental, temos, portanto, uma situação bastante característica de dissociação entre usuários diretos e usuários indiretos dos produtos ou serviços educativos.

Essa dissociação se torna mais aguda ainda quando se trata da produção concebida para alunos do segundo ciclo do ensino fundamental. De fato, a maioria dos editores de material paraescolar ressalta que o segundo ciclo do ensino fundamental é o nível mais difícil para eles. No primeiro ciclo, a influência dos pais pode exercer-se sem muita dificuldade, mais particularmente porque as editoras sabem dar a seus produtos um aspecto lúdico que permite aos pais suscitarem 0 interesse de seus filhos.

Com os alunos do segundo ciclo, as coisas complicam-se para os pais. Nessa idade, os alunos, que estão na pré-adolescência ou adolescência, não aceitam tão facilmente a mistura dos gêneros - aprendizagens na forma de jogos. Nessa fase a reivindicação de autonomia crescente na condução da própria vida, quer se trate da escolaridade ou do tempo livre, pode se tornar muito premente (Coridian, 2000). Com referência ao problema da autonomia dos usuários em forma- 
ção, poderíamos até dizer que, em certos casos, ao comprarem livros paraescolares, os pais esforçam-se em limitar a autonomia do aluno do segundo ciclo na qualidade de usuário escolar. Ao tentar fazer com que este se envolva mais nos estudos pessoais impostos pela escolaridade, estorvam uma possível utilização da escola que consiste em optar pela lei do mínimo esforço, utilização esta muito mal aceita tanto pelos pais como pelos docentes.

Na verdade, os próprios produtores de material paraescolar são sensíveis a essa dissociação entre usuários diretos e indiretos, como um dos editores que entrevistamos deixou claro ao falar dos livros ditos de metodologia, entendida, em nível do segundo ciclo, como a aprendizagem dos métodos de estudo que faltariam a muitos jovens. Valorizados entre os docentes graças aos documentalistas, tais livros conheceram um certo sucesso nos colégios, o que levou esse editor a pensar em organizar uma versão "grande público", destinada a um uso fora das salas de aula. Entretanto não era tão simples, pois, acrescentou ele: "Uma das perguntas essenciais que surgiram era: 'devemos nos dirigir aos pais ou aos filhos?'”

\section{Livros paraescolares para os próprios pais}

Se examinarmos, hoje em dia, o que as editoras paraescolares oferecem, constataremos que, de fato, elas agem de modo não exclusivo. Ao passo que as coleções de livros paraescolares clássicas se multiplicam e renovam, é agora possível encontrar livros paraescolares destinados mais diretamente aos pais.

Algumas editoras não se limitam mais a dirigir-se aos pais por meio de uma página de introdução e conselhos sobre o tema: "Como fazer com que seus filhos usem este livro". Hoje em dia, há editores que lhes propõem implementar um verdadeiro procedimento pedagógico parental, uma pedagogia caseira para monitorar e acompanhar os estudos escolares em casa.

Com o surgimento dessas novidades paraescolares, os pais acabam sendo ao mesmo tempo compradores e usuários desse tipo de livros, usuários diretos e indiretos. Uma das primeiras coleções desse tipo foi lançada pela Bordas, com um título muito evocativo e sem ambigüidade: J'aide mon enfant en... (Ajudo meu filho/minha filha em...), cujos primeiros títulos se dirigiam apenas às classes do primeiro ciclo do ensino fundamental. Essa coleção se apresenta como "Concebida para os pais, a partir de suas indagações e dos problemas 
que encontram para ajudar seus filhos. De fato, além de teorias e simples conselhos, os pais podem encontrar nela métodos concretos, objetivos precisos, exercícios fundamentais e explicações simples".

Esse tipo de livro se dirige a pais muito motivados em ajudar seus filhos no seu percurso escolar e que se preocupam em intervir do modo mais eficaz possível. Pois, como frisa o texto da apresentação citada acima, "os métodos mudaram de uma geração à outra, o vocabulário e as práticas pedagógicas evoluíram". Sem dúvida, nas entrevistas, os pais dizem que não se sentem necessariamente preparados para fazer seus filhos estudarem e que costumam se perguntar como intervir sem errar nem correr o risco de ir de encontro ao que estes escutam e aprendem na escola. Para muitos deles, trata-se de um verdadeiro quebracabeça (Meirieu, 2000).

Segundo os editores, essa evolução, ainda bastante limitada, justifica-se num duplo registro. Primeiro, uma lógica comercial impõe-se a cada um deles. De fato, as editoras confrontam-se com a necessidade de lançar regularmente novidades no mercado, mesmo se, geralmente, estas se limitam a retomar fórmulas já empregadas por outras, para não ser totalmente ausente em tal ou tal segmento de mercado. Ora, essa busca da inovação não tem apenas uma finalidade comercial. Como salientava um responsável editorial: "Existe uma demanda das famílias e pode-se respondê-la propondo livros em que encontrarão quilômetros de exercícios para se tranqüilizarem. Entretanto, de um ponto de vista editorial, é mais interessante criar coleções inovadoras, que sejam ferramentas pedagógicas mais sofisticadas, em que não se conceba 0 aluno entregue a si mesmo e em que se leve em conta a necessidade de compreensão dos pais que querem ajudar seus filhos...". Essa declaração do responsável do setor paraescolar para o ensino fundamental do primeiro ciclo de uma das maiores editoras é muito significativa. Com efeito, todos os editores adotam um discurso que justifica a seriedade pedagógica de sua própria produção e desqualifica mais ou menos explicitamente a de seus concorrentes. Procedimento relativamente natural, seríamos tentados a dizer, numa lógica em que cada um deve esforçar-se por ganhar partes de mercado ou pelo menos por preservar as que já conquistou.

Entretanto, talvez seja preciso aprofundar mais um pouco a análise que se pode esboçar dessa evolução no campo da edição paraescolar. Ante essa tentativa de aproximar compradores e usuários de produtos paraescolares, cabe perguntar-se se o procedimento dos editores não se inscreve numa orientação mais geral que corresponderia a um movi- 
mento rumo a uma forma de profissionalização do ofício de pai de aluno. De modo sintomático, Profession parents (Profissão pais) foi 0 título judiciosamente escolhido para uma revista lançada em 1994 no nicho da imprensa de informação e conselhos às famílias. Seu conteúdo revela que os pais a quem ela se dirige são antes os pais de alunos, esses pais dispostos a fazer de tudo para ajudar seus filhos a ter êxito na escola. Entretanto, preconizar o exercício de um verdadeiro ofício de pai de aluno, isto é, querer dar aos pais recursos que lhes permitam ser mais eficientes no acompanhamento e monitoramento da escolaridade, talvez não se limite simplesmente a atender uma demanda das próprias famílias.

\section{O êxito escolar a cargo dos pais?}

Como se sabe, com a massificação do ensino em todos os níveis, hoje em dia, a escola confronta-se com um problema maior: a heterogeneidade das populações de alunos de quem deve cuidar. Esse problema que, uns 20 anos atrás, já se colocava para o segundo ciclo do ensino fundamental, agora aflige 0 ensino médio e universitário.

Se 0 fato de parte dos pais recorrer a produtos paraescolares evidencia sua vontade de ajudar seus filhos a ter êxito na escola, a questão do estudo pessoal dos alunos não fica, entretanto, confinada à única esfera privada. Assim, há quem conteste os estudos em casa para os alunos do ensino fundamental porque contribuem para um êxito escolar desigual entre os alunos. Esse debate já se estendeu às reflexões sobre o sistema escolar e, por exemplo, em meados dos anos de 1990, a reforma ministerial - "Nouveau Contrat pour l'École" (Novo Contrato para a Escola) - incluía várias propostas visando a remediar essa desigualdade dos alunos ante os estudos pessoais exigidos pela escola, ao prever soluções que, no caso do ensino fundamental, pudessem ocorrer no âmbito escolar, depois das horas de aula. Vale lembrar que associações que atuam em bairros difíceis já tinham elaborado fórmulas de apoio escolar fora da escola, em benefício dos alunos cujas famílias não têm condição de garantir o monitoramento do estudo escolar.

Hoje em dia, a própria escola dá mostras de uma vontade de parceria com os pais ou as famílias. D. Glasman, ao analisar como a própria instituição escolar tende a designar os pais de forma diferenciada, ressaltou o uso muito conotado que a escola acaba fazendo dos termos 'famílias' ou 'pais'. O uso do vocábulo 'famílias' seria antes reservado à 
questão dos alunos em dificuldade, isto é, dos filhos de famílias "problemáticas", por sinal, geralmente famílias populares e/ ou imigradas. Em sentido oposto, 'pais' ou pais de alunos seria antes usado para designar alunos que não têm dificuldades escolares particulares, alunos integrados e que sabem aceitar as regras de funcionamento da escolaridade. D. Glasman afirma que, quando os agentes da instituição escolar falam em pais, eles se referem a um papel preciso, que esperam desses pais. Papel este, portanto, que apenas parte deles desempenha: os que, com relação a seus filhos, realizam "um conjunto de tarefas, materiais e simbólicas, que os preparam a freqüentar a escola de modo proveitoso" (Glasman, 1992). Em outras palavras, os pais de alunos seriam os que desempenham esse papel, que consiste em "transformar os filhos em alunos" e, por assim dizer, entregar produtos semi-acabados à escola, isto é, filhos escolarizáveis. Em compensação, com os filhos de certo número de famílias (problemáticas), tudo ainda estaria por fazer.

Para cumprir todas as tarefas que, hoje em dia, são suas, a escola parece precisar que amplas frações de pais tenham, cada vez mais, um comportamento de pais de alunos, isto é, façam parte dos pais nos quais a instituição pode amparar-se. Será que os editores de produtos paraescolares não participam, numa certa medida, para impor a idéia da conversão necessária dos pais em verdadeiros pais de alunos? De fato, por que se dirigem aos pais para thes propor, como diz certa propaganda de livro paraescolar, tornarem-se "os melhores parceiros dos docentes"? 0 que pode estar em jogo é uma versão individualizada da parceria pais/ escola, para uma fração de famílias que já manifestam esse interesse socialmente marcado, para a escola. Não por acaso, os meios editoriais costumam designar o mercado paraescolar como o mercado da angústia. A angústia de pais que receiam o fracasso escolar de seus filhos. Fracasso escolar que alguns, em contrapartida, preferem muito mais imputar às falhas da educação parental de parte dos alunos a vê-lo prioritariamente como o fracasso sintomático de um sistema escolar em crise.

Recebido em julho de 2003 e aprovado em agosto de 2003

\section{Notas}

1. A esse respeito, ver Chauvière \& Godbout (O rg.), L es usagers entre marché et citoyenneté, Paris, L'Harmattan, 1992. O capítulo que M. Barthélémy dedica à escola intitula-se "Les parents sont-ils les usagers du système scolaire?". 
2. N. do T.: No original, o autor fala em "écoliers" e "collégiens", o que corresponde a alunos do primeiro e do segundo ciclo do ensino fundamental, respectivamente.

3. N. do T.: Cadernos de exercícios das diferentes matérias escolares para o aluno poder estudar nas suas férias.

4. Guerin \& Muñoz , "Le multimédia pour la jeunesse: état de l'offre et perspectives", La revue des livres pour enfant, setembro 2000; "L'industrie du multimédia éducatif", D ossiers de l'audiovisuel (INA), n. 86, julho-agosto 1999; para uma visão mais geral das relações escola/ multimídia, ver Pouts-Lajus \& Riche-Magnier , "Les nouvelles technologies dans l'enseignement, rupture et continuité", em Van Zanten (O rg.), L 'école, l'état des savoirs, Paris, Editions La D écouverte, 2000.

\section{Referências bibliográficas}

BARTHÉLEMY, M. Les parents sont-ils usagers du système scolaire. In: CHAUVIÈRE, M.; GODBOUT, J.T. (D ir.). L es usagers entre marché et citoyenneté. Paris: L'Harmattan, 1992.

COLIN-MICHAUX, M.; CORIDIAN, C. Les produits éducatifs parasolaires: une réponse à l'inquiétude des familles? Paris: INRP, 1996.

CORIDIAN, C. Les collégiens, les lycéens et la scolarité. In: BOyER, R.; Coridian, C. M odes de vie collégiens et lycéens. Paris: INRP, 2000.

GLASMAN, D. Parents ou familles: critique d'un vocabulaire générique. Revue Française de Pédagogie, Paris, n. 100, 1992.

GLASMAN, D . et al. Cours particuliers et construction sociale de la scolarité. Paris: CNDP-FAS, 1994.

G LASMAN, D. L'accompagnement scolaire: sociologie d'une marge de l'école. Paris: PUF, 2001.

GUERIN; MUNÕZ. Le multimédia pour la jeunesse: état de l'offre et perspectives. L a Revue des Livres pour E nfants, Paris, n. 195, p. 61, sept. 2000.

MEIRIEU, P. L es devoirs à la maison: parents, enfants, enseignants pour en finir avec ce casse-tête. Paris: Syros, 2000.

MUSSO U, C.; VINUELA, A. L'industrie du multimedia éducatif. D ossiers de l'audiovisuel, Paris, n. 86, juil./ août. 1999.

POUTS-LAJUS, S.; RICHE-MAGNIER, M. Les nouvelles technologies dans l'enseignement, rupture et continuité. In: VAN ZanTEN, A. (Dir.). L'éole, état des savoirs. Paris: La D ecouverte, 2000. 